\title{
Microbe-Independent Entry of Oomycete RxLR Effectors and Fungal RxLR-Like Effectors Into Plant and Animal Cells Is Specific and Reproducible
}

\author{
Brett M. Tyler, ${ }^{1}$ Shiv D. Kale, ${ }^{2}$ Qunqing Wang, ${ }^{1}$ Kai Tao, ${ }^{1}$ Helen R. Clark, ${ }^{2}$ Kelly Drews, ${ }^{2}$ Vincenzo Antignani, ${ }^{2}$ \\ Amanda Rumore, ${ }^{2}$ Tristan Hayes, ${ }^{2}$ Jonathan M. Plett, ${ }^{3}$ Isabelle Fudal, ${ }^{4}$ Biao Gu, ${ }^{2,5}$ Qinghe Chen, ${ }^{2}$ \\ Katharyn J. Affeldt, ${ }^{6}$ Erwin Berthier, ${ }^{6}$ Gregory J. Fischer, ${ }^{6}$ Daolong Dou, ${ }^{2,7}$ Weixing Shan, ${ }^{5}$ \\ Nancy P. Keller, ${ }^{6}$ Francis Martin, ${ }^{3}$ Thierry Rouxel, ${ }^{4}$ and Christopher B. Lawrence ${ }^{2}$
}

${ }^{1}$ Center for Genome Research and Biocomputing, and Department of Botany and Plant Pathology, Oregon State University, Corvallis, OR 97331, U.S.A.; ${ }^{2}$ Virginia Bioinformatics Institute, Virginia Tech, Blacksburg, VA 24061, U.S.A.; ${ }^{3}$ Lab of Excellence ARBRE, UMR INRA/UHP 1136, Interactions Arbres/Micro-organismes, Centre INRA de Nancy, 54280 Champenoux, France; ${ }^{4}$ INRA-Bioger, Campus AgroParisTech, 78850 Thiverval-Grignon, France; ${ }^{5}$ College of Plant Protection and State Key Laboratory of Crop Stress Biology in Arid Areas, Northwest A\&F University, Yangling, Shaanxi 712100, China; ${ }^{6}$ Department of Medical Microbiology and Immunology, University of Wisconsin, Madison, WI 53706, U.S.A.; ${ }^{7}$ Department of Plant Pathology, Nanjing Agricultural University, Nanjing 210095, China

Submitted 18 February 2013. Accepted 25 February 2013.

A wide diversity of pathogens, mutualists, and pests of plant and animal hosts, including bacteria, fungi, oomycetes, apicomplexan parasites, nematodes, and insects produce effector proteins that enter the cytoplasm of host cells in order to modify the physiology of those cells, usually in favor of colonization (Torto-Alalibo et al. 2010). Two basic mechanisms for introducing those proteins into host cells have been observed: entry mechanisms dependent on microbe-derived machinery and entry mechanisms that utilize only host machinery (Tyler 2011). Examples of microbe-derived machinery include the type III, type IV, and type VI secretion machineries of gramnegative bacteria (Tseng et al. 2009) and rhoptries of apicomplexan parasites (Boothroyd and Dubremetz 2008). Examples of microbe-independent cell entry include type II secreted toxin proteins of bacteria that enter human cells by endocytosis following binding to glycosphingolipid receptors (Sandvig et al. 2010) and protein toxins secreted by necrotrophic plant pathogenic fungi, such as ToxA (Manning and Ciuffetti 2005). While large numbers of effector proteins have been identified from oomycete and fungal plant pathogens, the mechanisms by which these effector proteins enter plant cells continues to be a very active area of research. A major question has been whether or not entry by these effectors can occur inde-

Current address for Vincenzo Antignani: Molecular, Cellular, and Developmental Biology (MCDB), University of Michigan, Ann Arbor, MI 48109-1048, U.S.A.

Current address for Amanda Rumore: Department of Biology, Randolph College, Lynchburg, VA 24503, U.S.A.

Current address for Jonathan Plett: Hawkesbury Institute for the Environment, University of Western Sydney, Richmond, NSW 2753, Australia.

Current address for Qinghe Chen: Institute of Plant Protection, Fujian Academy of Agricultural Science, Fuzhou, Fujian 350003, China.

Corresponding author: B. M. Tyler; E-mail: brett.tyler@oregonstate.edu

(C) 2013 The American Phytopathological Society pendently of the microbe or requires machinery provided by the microbe (Ellis et al. 2006).

Much of the research on entry has centered around oomycete effectors that carry the N-terminal motifs RxLR (arginine, anything, leucine, arginine) and dEER (a string of acidic amino acids followed by arginine) (Kale and Tyler 2011; Tyler 2011). These motifs have been demonstrated to be required for efficient effector delivery during infection by Phytophthora sojae and P. infestans (Dou et al. 2008; Grouffaud et al. 2008; Whisson et al. 2007). Two classes of experiments have provided information that these effectors do not require the microbe for entry. The first are plant transient-expression experiments, by bombardment or agroinfiltration, in which the effector in question is secreted from the plant and must then reenter to trigger a measured response (usually cell death in the presence of a cognate resistance gene) (Anderson et al. 2012; Dou et al. 2008; Gu et al. 2011; Kale and Tyler 2010; Kale et al. 2010; Rafiqi et al. 2010; Sun et al. 2013). The second is to expose root tips or leaf tissue to purified effectors and then to measure entry microscopically using antibodies or by the presence of a chemical or protein fluorescent label attached to the effector (Dou et al. 2008; Kale et al. 2010; Plett et al. 2011; Wawra et al. 2012). In the case of $P$. sojae effector Avr1b, the same RxLR and dEER motif mutations that abolished entry by the effectors from the $P$. sojae transformants also abolished entry as measured by the transient expression and purified protein assays (Dou et al. 2008; Kale and Tyler 2010), supporting the conclusion that these assays are relevant to infection in vivo. Similar experiments have also identified fungal effectors that appear to enter plant cells in the absence of the microbe, via RxLR-like motifs ([R, K, H] x [L, M, I, F, W, Y], with no dEER-like motifs) (Gu et al. 2011; Kale and Tyler 2010; Plett et al. 2011). The demonstration that those oomycete and fungal effectors can bind host cell surface phosphatidyinositol-3phosphate (PI-3-P) via the RxLR motifs and that PI-3-P binding is required for entry has provided a mechanistic basis for RxLR-dependent entry (Kale et al. 2010; Sun et al. 2013). A 
surprising finding to emerge from these studies was that many of these oomycete and fungal effectors could enter not only plant cells but also human lung epithelial cells (Kale et al. 2010; Sun et al. 2013).

Recently, Wawra and associates (2013) presented a reexamination of whether the RxLR domain of oomycete RxLR effectors is sufficient for microbe-independent entry into host cells. The authors, from the van West, Kahmann, and Nuernberger labs, presented data in support of the conclusion that the RxLR domains of $P$. infestans Avr3a and of P. sojae Avr1b alone are NOT sufficient to enable microbe-independent entry of proteins into host and nonhost plant and animal cells. More specifically, they reported that they were unsuccessful in their attempts to reproduce key experiments previously reported by Dou and associates (2008) and Kale and associates (2010), in which green fluorescent protein (GFP) fusions to Avr1b and its RxLR domain were observed to enter soybean root cells and human lung epithelial cells. Instead, they reported that any fluorescent protein can be observed to enter soybean roots if exposed to the roots for an extended period. Data on nonspecific uptake into soybean roots were contributed by the Kahmann lab, negative uptake data for human and fish cells were contributed by the van West lab, and negative uptake data for Arabidopsis and Nicotiana cells were contributed by the Nuernberger lab.

In this letter, we summarize the wide diversity of data from different experimental systems that support the conclusion that Avr1b and its N-terminal domain can, in fact, enter host cells independently of the microbe. These include new, more detailed data that unambiguously demonstrate that the RxLR domain of Avrlb does show efficient and specific entry into soybean root cells and also into wheat leaf cells, at levels well above background nonspecific entry. We also summarize host cell entry experiments with a wide diversity of oomycete and fungal effectors with RxLR or RxLR-like motifs that have been independently carried out by the seven different labs that coauthored this letter. Finally we discuss possible reasons why Wawra and associates (2013) may have failed to observe specific cell entry.

The principal means for establishing whether entry of Avr1b into host cells is relevant to infection is based on mutagenesis experiments published by Dou and associates (2008). Avr1b has two RxLR motifs, RSLR at position 20 of the mature protein (called RXLR1) and RFLR at position 31 (called RXLR2). Furthermore, it has a dEER motif, EEDDAGER at position 37. Mutations in RXLR2 and dEER but not RXLR1 abolished the ability of the $A v r l b-1$ gene to confer avirulence on $P$. sojae when infecting soybean plants containing the cognate resistance gene Rps $1 b$. Transient expression of Avr1b proteins in soybean leaf cells by particle bombardment demonstrated that, when the proteins were expressed in the host cytoplasm, the RXLR2 and dEER mutants did not impair the ability of the protein to trigger cell death in the presence of Rpslb; thus, the mutations did not interfere with recognition of the protein by Rps1b. Further bombardment experiments in the presence of the Avr1b secretory leader revealed that, when the proteins were secreted from the host cells, the RXLR2 and dEER mutations did abolish Rps1b-mediated cell death; thus the RXLR2 and dEER motifs were inferred to be required for reentry. In order to demonstrate that the $\mathrm{N}$-terminal domain of Avr1b could deliver a C-terminal domain into soybean cells from an unambiguously external location, a purified GFP fusion protein carrying the Avrlb N-terminus (1 to 48) was exposed to soybean root tips. Entry of the protein into the root cells was observed microscopically only when the RXLR2 and dEER motifs were intact. Plasmolysis of the root cells confirmed that the protein was inside the cells. Kale and associates (2010) confirmed the root cell entry experiments of Dou and associates (2008), using full-length Avrlb protein and using more specific mutations of
RXLR2 (qFLR) that agreed with results of bombardment experiments by Dou and associates (2008). Furthermore, validating an observation by Shan and associates (2004), Kale and associates (2010) showed that full-length Avr1b protein could trigger cell death on leaves containing the Rps $1 b$ resistance gene but not on leaves lacking Rps $1 b$. The ability to trigger Rps1b-mediated cell death was abolished by the qFLR mutation and a dEER motif mutation, consistent with RxLR-dependent entry into soybean cells. The strong concordance among the four experiments- $P$. sojae transformants, particle bombardment transient expression, GFP fusion root entry, and leaf cell death-with respect to the effects of mutations in the RXLR2 and dEER motifs formed the basis for concluding that Avr1b could enter host cells in the absence of the microbe, as a result of the action of the RxLR and dEER motifs. The further demonstration that PI-3-P binding also depended on the RxLR and dEER motifs suggested that the mechanism of entry was lipid receptor-mediated endocytosis.

More detailed biophysical experiments with the Avr1b para$\log$ Avh5 (Sun et al. 2013), clarified that PI-3-P binding and entry into soybean root cells and human lung cells depended not only on the N-terminal RxLR domain but also on residues in the C-terminus. These root entry experiments were performed using Dylight488-labeled Avh5 and shorter incubation times $(2 \mathrm{~h})$, ruling out artifacts resulting from the use of GFP fusions or long incubation times.

The original description of microbe-independent cell entry made with Avrlb led to the subsequent observation of microbeindependent entry by a wide diversity of oomycete and fungal effectors. The subsequent reports used the same methodologies pioneered for Avrlb, including bombardment assays and uptake of fluorescent fusion proteins into soybean root and leaf cells and into human lung epithelial cells. These subsequent discoveries thus provide further diverse and independent validation of the initial discovery of microbe-independent entry by Avr1b. Here, we summarize the experience of seven different laboratories and sixteen researchers in those laboratories in documenting microbe-independent entry by oomycete and fungal effectors into plant and animal cells, using the approaches developed using Avr1b.

B. M. Tyler, Virginia Tech. Subsequent to the Avr1b experiments, soybean and human cell entry experiments were performed with Avr1k (P. sojae Avh331), Avr2 (Fusarium oxysporum), AvrLm6 (Leptosphaeria maculans), AvrL567 (Melampsora lini) (Kale et al. 2010), MiSSP7 (Plett et al. 2011), AvrLm4-7 (Leptosphaeria maculans) (unpublished), Af2 (Aspergillus fumigatus) (unpublished), Af3 (Aspergillus fumigatus) (unpublished), and a secreted allergen (Alternaria alternata) (unpublished). Root and human cell entry experiments were conducted by B. Gu, V. Antignani, and Q. Chen in addition to $\mathrm{S}$. Kale, as indicated in Table 1 . In each case, specific entry was established by use of mutations in RxLR (-like) motifs and inhibition by PI-3-P-binding proteins. The demonstration that AvrL567 enters plant cells independently of the microbe, dependent on the RXLR-like motif RFYR, was independently validated (Rafiqi et al. 2010).

B. M. Tyler, Oregon State. In early 2012, the Tyler lab moved to Oregon State, while S. Kale remained at Virginia Tech. Subsequently, the root cell entry assays and PI-3-P binding assays with the Avr1b RxLR domain were both reestablished after a period of trouble shooting. For example, the growth conditions and age of the soybean plants, the quality of the protein preparations, and buffer and $\mathrm{pH}$ of the protein solution, and the time and temperature of incubation of the roots all were important for successful root uptake experiments. Q. Wang and K. Tao conducted the root cell entry assays. In particular, they conducted the experiment shown in Figure 1, in which GFP alone, 
Avr1b RxLR domain fused to GFP, or the Avr1b RxLR domain with the mutation RFLR $\rightarrow$ AAAA, were exposed to soybean root tips. mCherry protein was mixed with each GFP protein in order to observe the level of nonspecific entry into the same cells that were being observed for specific entry. The results demonstrate that the intact Avr1b-GFP fusion but not GFP itself or the Avr1b RxLR mutant accumulate in soybean roots to a substantially higher level than mCherry.

S. Kale, Virginia Tech. S. Kale opened his own lab at Virginia Tech in the summer of 2011. Subsequently he and his lab members, H. Clark and K. Drews, conducted soybean and human cell entry experiments with Avr1b, Avh5, AvrLm4-7, Af2, Af3, and an Alternaria allergen. In particular, his lab conducted the experiments shown in Figure 2, which demonstrate that the Avr1b RxLR domain labeled with Dylight 488 but not the Avr1b RxLR mutant protein labeled with Dylight550 could enter soybean root cells and wheat leaf cells after only $2 \mathrm{~h}$, when the two proteins were incubated together within the same tissues.

C. B. Lawrence, Virginia Tech. The Lawrence lab conducts research on the interactions of human lung cells with fungal proteins. Lab members A. Rumore and T. Hayes independently carried out the initial human cell entry experiments with Af2 and the Alternaria allergen, including validation of specific entry using mutations in RxLR-like motifs and inhibition by PI-3-P-binding proteins. Proteins were either directly labeled with DyLight 488 or were fused with reporters GFP and mCherry. Moreover, they have confirmed PI-3-P-binding to these proteins and the importance of the RxLR-like motif using lipid blots and isothermal titration calorimetry (unpublished).

W. Shan, Northwest A\&F University, China. The Shan lab studies interactions of plants with oomycete and fungal plant pathogens. W. Shan conducted the first Avr1b cell entry experiments into soybean leaves while in B. Tyler's lab at the University of California, Davis (Shan et al. 2004), which were later replicated by Kale and associates (2010). Lab member B. $\mathrm{Gu}$ visited the Tyler lab at Virginia Tech, where he carried out numerous root cell entry experiments, including replicates of those described in Kale and associates (2010), and, particularly, experiments with Avr1bNt-GFP. After returning to the Shan lab, he independently replicated the cell entry experiments with Avr1bNt-GFP and carried out new experiments documenting entry of a candidate wheat rust effector, Ps87, into soybean root cells dependent on an RxLR-like motif. Both those results are illustrated in Figure 4 of $\mathrm{Gu}$ and associates (2011).

F. Martin, INRA, Nancy. The Martin lab studies interactions between trees and the mutualistic ectomycorrhizal fungus
Laccaria bicolor. They demonstrated that MYCORRHIZAL iNDUCED SMALL SECRETED PROTEIN 7 (MiSSP7), the most highly symbiosis-upregulated gene from $L$. bicolor (Martin et al. 2008), encodes an effector protein indispensable for the establishment of mutualism (Plett et al. 2011). J. Plett showed that 5,6-carboxyfluorescein (FAM)-tagged MiSSP7 protein is actively taken up into roots of host (Populus trichocarpa) and nonhost plants (e.g., Arabidopsis thaliana, Glycine max) and poplar suspension cells in less than $20 \mathrm{~min}$ in the absence of the fungus (Plett et al. 2011). Then, synthetic and recombinant MiSSP7 proteins were both found to enter host cells. Numerous controls were performed in the Martin and Tyler labs to ensure that MiSSP7 entry was not artifactual, including the use of deletion and substitution mutations in the RALG (RxLR-like) motif and inhibition by PI-3-P-binding proteins and many other inhibitors. Under the same experimental conditions, other MiSSPs, such as MiSSP8 and hydrophobins, did not enter poplar root cells (J. Plett and S. Kale, unpublished). To ensure that MiSSP7 entry was not due to passive diffusion due to the small size of the protein, heat-killed poplar roots were shown to be unable to take up the protein.

T. Rouxel, INRA, Thiverval-Grignon. The Rouxel lab studies effectors produced by Leptosphaeria maculans, a hemibiotrophic fungal pathogen of oilseed rape (Brassica napus). Cell entry experiments into oilseed rape roots were performed by I. Fudal using a concentration of $70 \mu \mathrm{g} / \mathrm{ml}$ of full-length AvrLm4-7 protein coupled to 5,6FAM, with an incubation time of $3 \mathrm{~h}$. The Kale lab did similar experiments with soybean roots and DyLight488-labeled proteins. In both cases, rapid entry of the proteins was observed within 2 to $3 \mathrm{~h}$, and in the case of experiments on soybean roots, specific entry was established using mutations in RxLR-like and C-terminal motifs (unpublished).

N. Keller, University of Wisconsin, Madison. The Keller lab studies the interaction of Aspergillus fumigatus with animals. They identified the putative effector Af3 bioinformatically and shared the sequence with the Tyler lab. Specific entry of Af3GFP fusions into human lung epithelial cells was demonstrated first in the Tyler lab and was then validated in the Keller lab (unpublished).

There are several possible technical explanations why Wawra and associates (2013) may have obtained the negative results that they report.

i) The Avr1b-GFP protein used for the experiment may have been inactive or degraded. It appears that just a single preparation of Avr1b-GFP protein, prepared in the van West lab and distributed to the other collaborators, was used for all the stud-

Table 1. Selected host cell entry experiments that have been reproduced by individual researchers within and among different labs

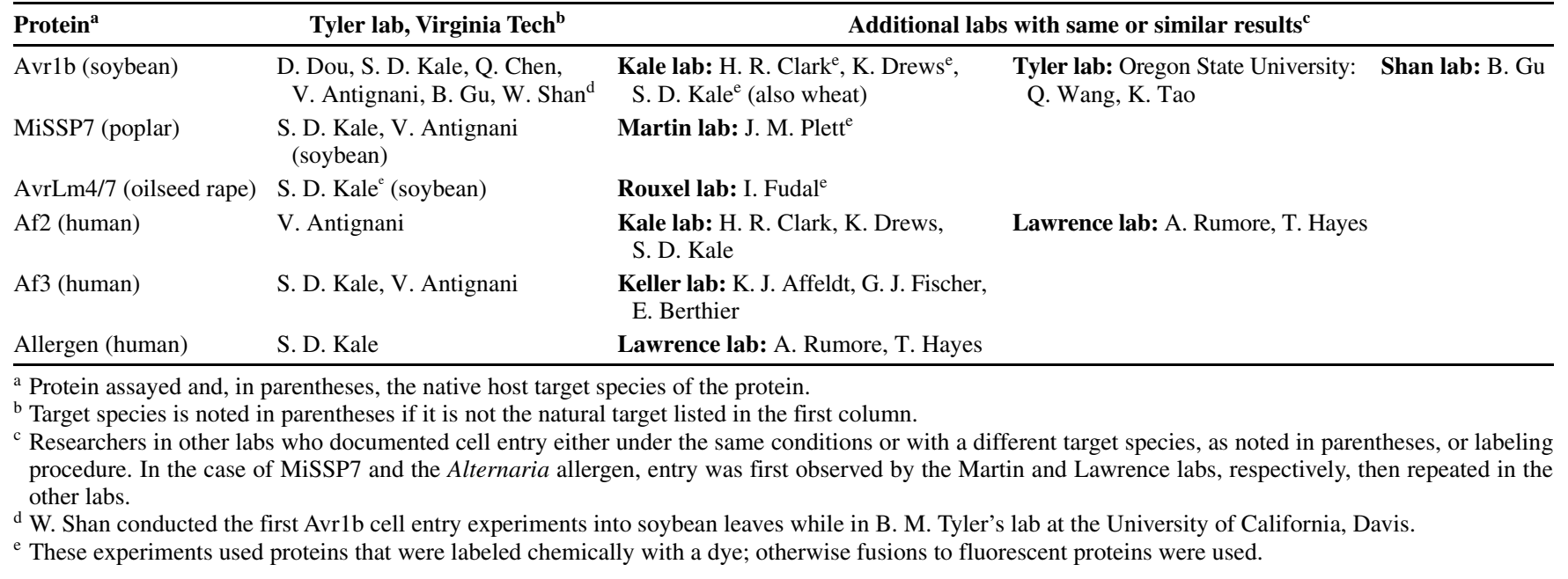


ies. If this protein preparation was inactive, then all experiments in the study would be negative. The isolation procedure used by the authors is quite different than that used by Dou and associates (2008) and Kale and associates (2010), so it is possible the differences in isolation led to differences in activity. It is the experience of the Tyler, Kale, Lawrence, and Rouxel labs that effector preparations stored for any length of time soon lose activity, so it is our routine practice to use recently prepared proteins for all assays. Protein degradation can be a problem also. Although Wawra and associates (2013) showed mass spectrometry data to validate the quality of their initial preparation of protein, they did not use an assay such as Western blots to check the intactness of the protein immediately prior to and during the cell entry assays. Thus, it remains possible the protein was already degraded prior to the start of the experiments or was rapidly degraded following exposure to the target cells. Kale and associates (2010) and Plett and associates (2011) did use Western blots to check the intactness of the proteins before and after their entry assays.

ii) In the case of soybean, the roots may not have been prepared in a way that left them competent for specific cell entry. The wheat germ agglutinin positive control used for the human cell experiments failed to enter the soybean roots. Furthermore, Wawra and associates (2013) did not utilize the Arg9-GFP control developed by Chang and associates (2005) and used by Dou and Kale and their associates (2008, 2010). The experience of the Tyler lab (at both Virginia Tech and Oregon State) is that batches of roots are occasionally encountered that fail to exhibit specific RxLR-dependent entry activity and instead exhibit only the weak nonspecific entry reported by Wawra and associates (2013). As documented in our publications, entry by the numerous oomycete and fungal proteins we have studied has, in every case, been validated to be specific by use of proteins with RxLR mutations and by the use of PI-3-P-blocking inhibitors. In our published figures, we have routinely used stringent confocal microscope settings that exclude nonspecific background entry. Furthermore, in recent work (Sun et al. 2013, Fig. 2), we have introduced the use of propidium iodide to identify cells that may have died and, hence, may take up protein nonspecifically.

iii) Wawra and associates (2013) observed no entry into human A549 lung epithelial cells. However, our experience (Tyler, Kale, Lawrence, and Keller labs) is that entry into these cells is straightforward to observe. Even if their effector protein preparations were not inactive, it is likely that the presence of $10 \%$ fetal bovine serum (FBS) in the medium during their uptake assays would have interfered with entry. We routinely incubate our cells in serum-free medium for at least $2 \mathrm{~h}$, before adding fluorescent proteins for entry assays. It seems likely that the high concentration of proteins and lipids in the FBS could interfere with the binding and entry of lipid-binding proteins.

iv) We (Tyler lab) have occasionally encountered the GFPrelated precipitation problem mentioned by Wawra and associates (2013). However, as noted by the authors, there is no correlation between precipitation and entry. GFP-mediated precipitation certainly cannot explain entry that is abolished by the presence of RxLR mutations or the presence of PI-3-Pbinding proteins (Dou et al. 2008; Gu et al. 2011; Kale et al. 2010). Furthermore, we have observed strong, specific entry within 2 to $3 \mathrm{~h}$, when using chemically-labeled Avr1b (Fig. 2), Avh5 (Sun et al. 2013), or MiSSP7 (Plett et al. 2011), clearly ruling out GFP-mediated precipitation as a cause of nonspecific entry. Moreover, we have shown in multiple repeated experiments with several proteins that the RxLR-dependent cell entry phenomenon occurs within minutes in multiple lung epithelial cell types, namely immortalized cell lines (A549 and BEAS-2b) and primary cells derived directly from human (NHBE) (A. Rumore, T. Hayes, and C. B. Lawrence, unpublished).

v) Wawra and associates (2013) reported being unable to observe specific entry into Arabidopsis root cells or Nicotiana benthamiana leaf cells. We also have never observed entry into $N$. benthamiana cells and have only observed entry into Arabidopsis cells by MiSSP7 (Plett et al. 2011). Either the correct way to prepare these tissues to preserve their specific uptake activity has not yet been found or else the cells of these
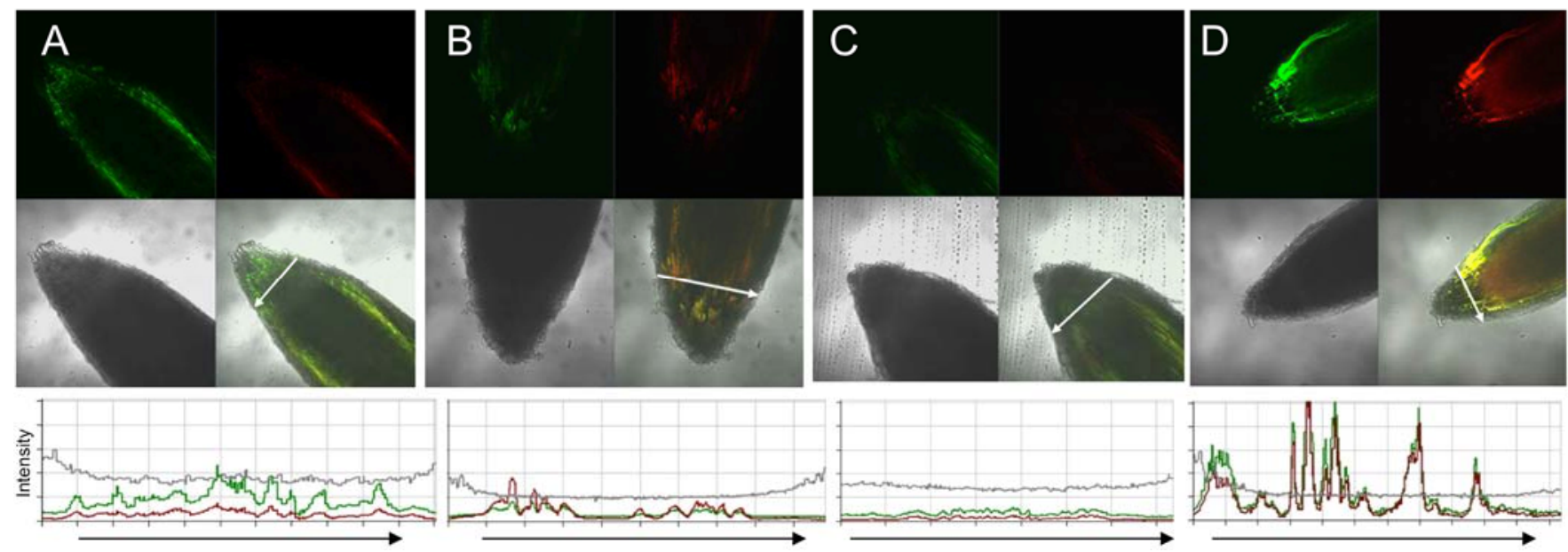

Fig. 1. Specific microbe-independent entry of Avr1bNt-GFP fusions into soybean root cells. A, Avr1b N-terminus (residues 1 to 50 of the mature protein) fused to green fluorescent protein (GFP) mixed with mCherry protein. B, Avrlb N-terminus (residues 1 to 50) with RSLR $\rightarrow$ AAAA and RFLR $\rightarrow$ AAAA mutations, fused to GFP mixed with mCherry protein. $\mathbf{C}$ and $\mathbf{D}$, GFP protein (no fusions) mixed with mCherry protein. Purified fusion proteins ( 0.5 $\mathrm{mg} / \mathrm{ml}$ each) were incubated with soybean ('Williams') root tips, for $12 \mathrm{~h}$ in the dark at $23^{\circ} \mathrm{C}$ in phosphate-buffered saline (PBS; $10 \mathrm{mM} \mathrm{Na}$ phosphate, 138 $\mathrm{mM} \mathrm{NaCl}, 2.7 \mathrm{mM} \mathrm{KCl}$, adjusted to $\mathrm{pH} 6.8$ with $\mathrm{HCl}$; Sigma P5368) and were then washed four times for $1 \mathrm{~h}$ each in PBS, $\mathrm{pH} 6.8$, at $23^{\circ} \mathrm{C}$. Proteins all carried C-terminal $\mathrm{His}_{6}$ tags and were purified as described (Kale et al. 2010). The roots were imaged with a Zeiss LSM 510 confocal microscope, with an excitation wavelength of $488 \mathrm{~nm}$ and emission window of 505 to $530 \mathrm{~nm}$ for GFP or an excitation wavelength of $543 \mathrm{~nm}$ and emission window of $>560 \mathrm{~nm}$ for mCherry. Master gain was set to 500 for A to C and to 650 for D. In each figure section, the upper left panel shows the GFP image, the upper right the mCherry image, the middle left, the light image, the middle right the overlay of GFP, mCherry, and light images, and the bottom panel shows an intensity scan of the GFP (green), mCherry (red), and light (gray) channels along the transect shown by the white arrow in the overlay image. The intensity scale for the scans are all on the same scale. The experiments shown in this figure were conducted at Oregon State University. 
two species simply never exhibit a high-enough activity to detect entry using fluorescent proteins. On the other hand, we could readily observe RxLR-dependent entry into poplar root cells (Plett et al. 2011), into rapeseed root cells (I. Fudal and T. Rouxel, unpublished) and into wheat leaf cells (Fig. 2), indicating that a high level of specific uptake activity is not restricted to soybean. We have not tested RxLR-dependent entry into fish cells.
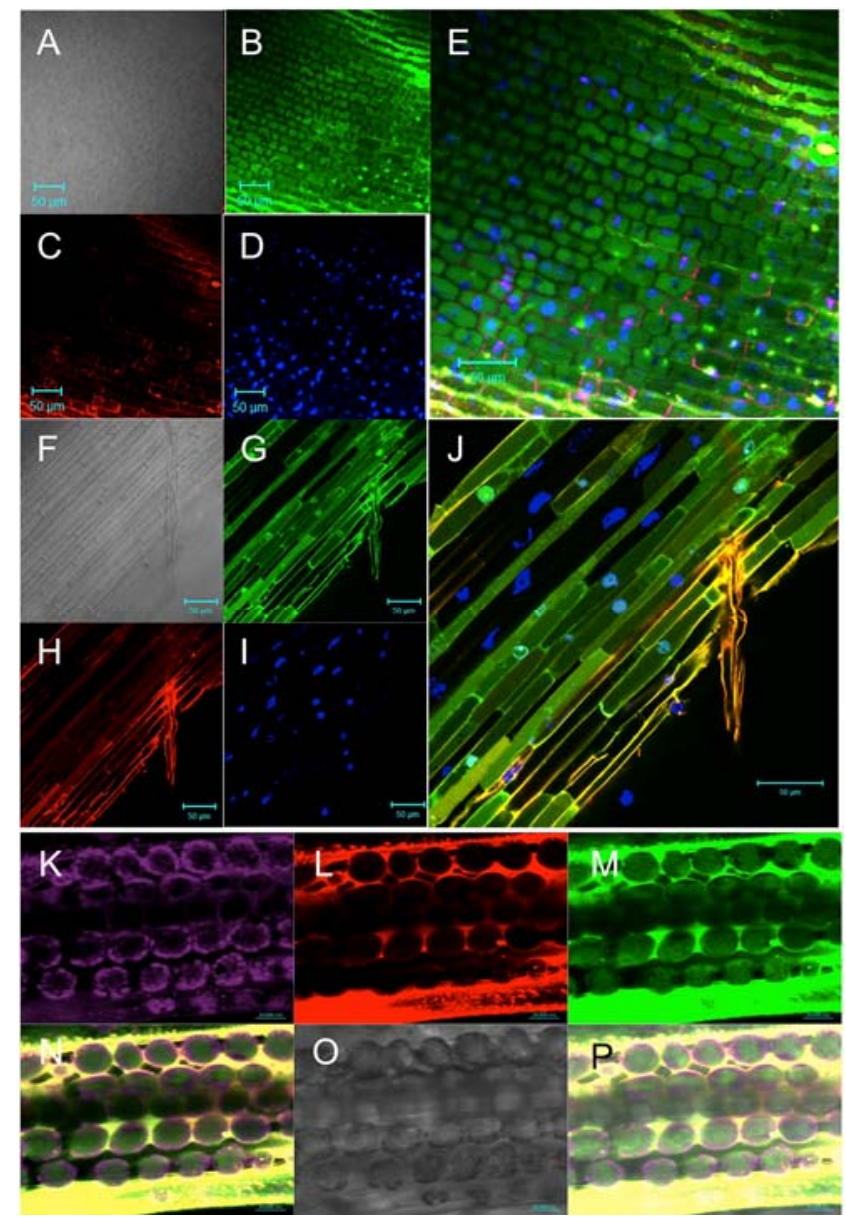

Fig. 2. Specific microbe-independent entry of AvrlbNt proteins into soybean root cells and wheat leaf cells. A to E, Soybean root entry by Avrlb N-terminus (residues 1 to 50 ) labeled by Dylight 488 and counter-stained with propidium iodide and 4',6-diamidino-2-phenylindole (DAPI). F to J, Soybean root entry by Avr1b N-terminus (residues 1 to 50) labeled by Dylight 488 , mixed with Avrlb N-terminus with RFLR $\rightarrow$ qFLR mutation labeled with DyLight550 and counter-stained with DAPI. A and F, light image; B and G, Dylight488 image; C, propidium image; H, Dylight550 image; D and I, DAPI image; $\mathrm{E}$ and $\mathrm{J}$, overlay of the three fluorescent images. In A to J, purified fusion proteins $(0.4 \mathrm{mg} / \mathrm{ml}$ each) were incubated with soybean ("Williams') root tips for $2 \mathrm{~h}$ at $25^{\circ} \mathrm{C}$ in phosphate-buffered saline (PBS) buffer adjusted to $\mathrm{pH} 7.2$ and were then washed for $15 \mathrm{~min}$ in formalin (PBS $+10 \%$ formaldehyde) containing $0.2 \mu \mathrm{g} / \mathrm{ml}$ propidium iodide (A to E only) and 0.4 $\mu \mathrm{g} / \mathrm{ml}$ DAPI. $\mathbf{K}$ to $\mathbf{P}$, Wheat leaf cell entry by Avr1b N-terminus (residues 1 to 50) labeled by Dylight 488 mixed with Avrlb N-terminus (residues 1 to 50) with RFLR $\rightarrow$ qFLR mutation labeled by Dylight550. Purified fusion proteins $(0.4 \mathrm{mg} / \mathrm{ml}$ each) in PBS buffer adjusted to $\mathrm{pH} 7.2$ were infiltrated with a blunt syringe into approximately nine-day-old wheat seedling leaves. Leaves were imaged after $6 \mathrm{~h}$ without washing. $\mathrm{K}$, chloroplast fluorescence (excitation $488 \mathrm{~nm}$; emission meta filter 675 to $715 \mathrm{~nm}$ ); L, Dylight550 image (excitation $543 \mathrm{~nm}$; emission window 585 to $615 \mathrm{~nm}$; gain 600 to 654 ; digital offset -0.1 to 0); M, Dylight488 image (excitation $488 \mathrm{~nm}$; emission window 505 to $530 \mathrm{~nm}$; gain 580 to 610 ; digital offset -0.1 to 0 ); $\mathrm{N}$, overlay of $\mathrm{K}$ to $\mathrm{M}$; O, light image; overlay of $\mathrm{N}$ and $\mathrm{O}$. Labeling of proteins with Dylight dyes was as described (Sun et al., 2013). The experiments shown in this figure were conducted at Virginia Tech, using a Zeiss LSM 510 Meta confocal microscope.
In conclusion, it is the overwhelming experience of the sixteen researchers and seven labs that are coauthors of this letter that microbe-independent entry of oomycete and fungal effectors into both plant and animal cells is specific and independently reproducible. We welcome a vigorous, ongoing, and constructive debate on the question of how effectors enter host cells, as a means for stimulating research into this extremely important topic. We renew our invitation, expressed many times in the past, for researchers from the van West, Kahmann, and Nuernberger labs to visit our labs and learn the technical details of how we assay specific entry.

\section{ACKNOWLEDGMENTS}

This work was supported by the National Science Foundation Grant IOS-0924861 (to B. M. Tyler), the National Institutes of Health NIAID grant 1R21A1094071-01 (to C. B. Lawrence), and by funds from the Virginia Bioinformatics Institute and Oregon State University. N. P. Keller, K. J. Affeldt, E. Berthier, and G. J. Fischer acknowledge support from NSF IOS-0965649 and the American Asthma Foundation.

\section{LITERATURE CITED}

Anderson, R. G., Casady, M. S., Fee, R. A., Vaughan, M. M., Deb, D., Fedkenheuer, K., Huffaker, A., Schmelz, E. A., Tyler, B. M., and McDowell, J. M. 2012. Homologous RXLR effectors from Hyaloperonospora arabidopsidis and Phytophthora sojae suppress immunity in distantly related plants. Plant J. 72:882-893.

Boothroyd, J. C., and Dubremetz, J. F. 2008. Kiss and spit: The dual roles of Toxoplasma rhoptries. Nat. Rev. Microbiol. 6:79-88.

Chang, M., Chou, J. C., and Lee, H. J. 2005. Cellular internalization of fluorescent proteins via arginine-rich intracellular delivery peptide in plant cells. Plant Cell Physiol. 46:482-488.

Dou, D., Kale, S. D., Wang, X., Jiang, R. H. Y., Bruce, N. A., Arredondo, F. D., Zhang, X., and Tyler, B. M. 2008. RXLR-mediated entry of Phy tophthora sojae effector Avr1b into soybean cells does not require pathogen-encoded machinery. Plant Cell 20:1930-1947.

Ellis, J., Catanzariti, A. M., and Dodds, P. 2006. The problem of how fungal and oomycete avirulence proteins enter plant cells. Trends Plant Sci. 11:61-63.

Grouffaud, S., van West, P., Avrova, A. O., Birch, P. R., and Whisson, S. C. 2008. Plasmodium falciparum and Hyaloperonospora parasitica effector translocation motifs are functional in Phytophthora infestans. Microbiology 154:3743-3751.

Gu, B., Kale, S. D., Wang, Q., Pan, Q., Cao, H., Meng, Y., Kang, Z., Tyler, B. M., and Shan, W. 2011. Rust secreted protein Ps87 is conserved in diverse fungal pathogens and contains an RXLR-like motif sufficient for translocation into plant cells. PLoS ONE 6:e27217. Published online.

Kale, S. D., and Tyler, B. M. 2010. Assaying effector function in planta using double-barreled particle bombardment. Page in press in: Methods in Molecular Biology. The Plant Immune Response. J.M. McDowell, ed. Humana, Totowa, NJ.

Kale, S. D., and Tyler, B. M. 2011. Entry of oomycete and fungal effectors into plant and animal cells. Cell. Microbiol. 13:1839-1848.

Kale, S. D., Gu, B., Capelluto, D. G. S., Dou, D.-L., Feldman, E., Rumore, A., Arredondo, F. D., Hanlon, R., Fudal, I., Rouxel, T., Lawrence, C. B. Shan, W.-X., and Tyler, B. M. 2010. External lipid PI-3-P mediates entry of eukaryotic pathogen effectors into plant and animal host cells. Cell 142:284-295.

Manning, V. A., and Ciuffetti, L. M. 2005. Localization of Ptr ToxA produced by Pyrenophora tritici-repentis reveals protein import into wheat mesophyll cells. Plant Cell 17:3203-3212.

Martin, F., Aerts, A., Ahren, D., Brun, A., Danchin, E. G., Duchaussoy, F., Gibon, J., Kohler, A., Lindquist, E., Pereda, V., Salamov, A., Shapiro, H J., Wuyts, J., Blaudez, D., Buee, M., Brokstein, P., Canback, B., Cohen, D., Courty, P. E., Coutinho, P. M., Delaruelle, C., Detter, J. C., Deveau, A., DiFazio, S., Duplessis, S., Fraissinet-Tachet, L., Lucic, E., FreyKlett, P., Fourrey, C., Feussner, I., Gay, G., Grimwood, J., Hoegger, P. J., Jain, P., Kilaru, S., Labbe, J., Lin, Y. C., Legue, V., Le Tacon, F., Marmeisse, R., Melayah, D., Montanini, B., Muratet, M., Nehls, U., Niculita-Hirzel, H., Oudot-Le Secq, M. P., Peter, M., Quesneville, H., Rajashekar, B., Reich, M., Rouhier, N., Schmutz, J., Yin, T., Chalot, M., Henrissat, B., Kues, U., Lucas, S., Van de Peer, Y., Podila, G. K., Polle, A., Pukkila, P. J., Richardson, P. M., Rouze, P., Sanders, I. R., Stajich, J. E., Tunlid, A., Tuskan, G., and Grigoriev, I. V. 2008. The genome of 
Laccaria bicolor provides insights into mycorrhizal symbiosis. Nature 452:88-92.

Plett, J. M., Kemppainen, M., Kale, S. D., Kohler, A., Legué, V., Brun, A., Tyler, B. M., Pardo, A. G., and Martin, F. 2011. A secreted effector protein of Laccaria bicolor is required for symbiosis development. Curr. Biol. 21:1197-1203.

Rafiqi, M., Gan, P. H., Ravensdale, M., Lawrence, G. J., Ellis, J. G., Jones, D. A., Hardham, A. R., and Dodds, P. N. 2010. Internalization of flax rust avirulence proteins into flax and tobacco cells can occur in the absence of the pathogen. Plant Cell 22:2017-2032.

Sandvig, K., Torgersen, M. L., Engedal, N., Skotland, T., and Iversen, T. G. 2010. Protein toxins from plants and bacteria: probes for intracellular transport and tools in medicine. FEBS (Fed. Eur. Biochem. Soc.) Lett. 584:2626-2634.

Shan, W., Cao, M., Leung, D., and Tyler, B. M. 2004. The Avrlb locus of Phytophthora sojae encodes an elicitor and a regulator required for avirulence on soybean plants carrying resistance gene Rpslb. Mol. Plant Microbe Interact. 17:394-403.

Sun, F., Kale, S. D., Azurmendi, H. F., Li, D., Tyler, B. M., and Capelluto, D. G. S. 2013. Structural basis for interactions of the Phytophthora sojae RXLR effector Avh5 with phosphatidylinositol 3-phosphate and for host cell entry. Mol. Plant-Microbe Interact. 26:330-344.

Torto-Alalibo, T., Collmer, C. W., Gwinn-Giglio, M., Lindeberg, M., Meng, S.-W., Chibucos, M. C., Tseng, T.-T., Lomax, J., Biehl, B., Ireland, A., Bird, D., Dean, R. A., Glasner, J. D., Perna, N., Setubal, J. C., Collmer,
A., and Tyler, B. M. 2010. Unifying themes in microbial associations with animal and plant hosts described using the Gene Ontology. Microbiol. Molec. Biol. Rev. 74:479-503.

Tseng, T. T., Tyler, B. M., and Setubal, J. C. 2009. Protein secretion systems in bacterial-host associations, and their description in the Gene Ontology. BMC Microbiol. 9 Suppl 1:S2.

Tyler, B. M. 2011. Entry of oomycete and fungal effectors into host cells. Pages 243-278 in: Effectors in Plant-Microbe Interactions. F. Martin and S. Kamoun, eds. Wiley-Blackwell, Oxford.

Wawra, S., Bain, J., Durward, E., de Bruijn, I., Minor, K. L., Matena, A., Löbach, L., Whisson, S. C., Bayer, P., Porter, A. J., Birch, P. R. J., Secombes, C. J., and van West, P. 2012. Host-targeting protein 1 (SpHtp1) from the oomycete Saprolegnia parasitica translocates specifically into fish cells in a tyrosine- $O$-sulphate-dependent manner. Proc. Natl. Acad. Sci. U.S.A. 109: 2096-2101.

Wawra, S., Djamei, A., Kuefner, I., Nuernberger, T., Kahmann, R., and van West, P. 2013. In vitro translocation experiments with RxLR-reporter fusion proteins of Avrlb from Phytophthora sojae and AVR3a from Phytophthora infestans fail to demonstrate autonomous uptake in plant and animal cells. Mol. Plant-Microbe Interact. 26: 528-536.

Whisson, S. C., Boevink, P. C., Moleleki, L., Avrova, A. O., Morales, J. G., Gilroy, E. M., Armstrong, M. R., Grouffaud, S., van West, P., Chapman, S., Hein, I., Toth, I. K., Pritchard, L., and Birch, P. R. J. 2007. A translocation signal for delivery of oomycete effector proteins into host plant cells. Nature 450:115-119. 